\title{
Development and evaluation of a hospital management practice rating scale
}

\author{
Yidan Zhu ${ }^{1}$, Ruya Guo ${ }^{2}$, Lixia Dou ${ }^{3}$, Yifei Zhao ${ }^{4}$, Shenshen $\mathrm{Li}^{4}$, Yujia Qiao ${ }^{1}$, Yangfeng $\mathrm{Wu}^{* 1,4,5}$ \\ ${ }^{1}$ Department of Epidemiology and Biostatistics, School of Public Health, Peking University, Beijing, China \\ ${ }^{2}$ Research Department, Peking University Third Hospital, Beijing, China \\ ${ }^{3}$ National Center for Women and Children's Health, China CDC, Beijing, China \\ ${ }^{4}$ The George Institute for Global Health at Peking University Health Science Center (PUHSC), Beijing, China \\ ${ }^{5}$ Peking University Clinical Research Institute, Beijing, China
}

Received: November 15, 2017

DOI: $10.5430 /$ jha.v7n1p9
Accepted: January 5, $2018 \quad$ Online Published: January 18, 2018

URL: https://doi.org/10.5430/jha.v7n1p9

\begin{abstract}
Background: Lacking methods to quantify the inter-hospital variance in hospital management practice (HMP) is a bottle neck for research on HMP and quality of care. This study aims to quantify the inter-hospital variance in HMP by developing a novel rating scale of HMP and evaluating its feasibility, reliability and validity.

Methods: Based on the theory of hospital management, we developed a HMP rating scale with 4 dimensions: Target, operations, performance and talent management. We used questionnaires to collect relevant information from the hospital director, the medical affairs director, the head of the department of cardiology, and a cardiologist. And we also requested a list of administration documents. For validation of the scale, we applied it to 101 hospitals that had participated in the Third Phase of the Clinical Pathways in Acute Coronary Syndromes Study (CPACS-3) in 2013 and repeated it in 2014.

Results: The HMP rating scale includes 17 indicators and 47 sub-indicators in the four dimensions; $85 \%$ and $97 \%$ of hospitals responded to the first and second survey respectively. A high degree of the test-retest reliability for the overall score $($ ICC $=0.8)$ was found between the two time points. Both split-half and Cronbach' $\alpha$ coefficient of the overall score exceeded 0.85 . Cumulative percentage of variance in all dimensions was above $60 \%$, and factors extracted in each dimension were highly consistent with the designed indicators and sub-indicators. The overall HMP score was different between hospital groups with different revenues, patients' hospital stays, and number of clinical pathways (All $p$ values $<.01$ ).

Conclusions: The HMP rating scale was demonstrated reliable, valid, and responsive, but future studies with larger sample size in different settings are needed to confirm the study findings.
\end{abstract}

Key Words: Hospital management practices, Rating scale, Reliability, Validity, China

\section{INTRODUCTION}

It is well recognized that quality health care delivery has not only clinical challenges, but also management challenges. Previous studies have shown that the optimizing of management strategies could improve the quality of medical care and patient satisfaction. ${ }^{[1-4]}$ In fact, patients' outcomes rely not only on "hard wares" such as medical technologies and clinical skills of medical staff, but also on "soft wares" such as hospital management practices. Existing data have shown that hospitals with high-level medical quality usually have

\footnotetext{
* Correspondence: Yangfeng Wu; Email: ywu@georgeinstitute.org.cn; Address: The George Institute for Global Health at Peking University Health Science Center, No. 6 Zhichun Rd Haidian District, Beijing, 100088, China.
} 
a higher-level of management performance in fields such as goal-setting, medical environment and performance incentives. ${ }^{[5-9]}$ However, this evidence is derived mainly from limited aspects of hospital management and few studies have provided sufficient methodological details to determine how the linkages were made. ${ }^{[10]}$ Also, the methods of evaluation of management varies among studies. Thus, although such relationship between management practice and quality of care may be true, it has always been an international argument. ${ }^{[11]}$

To be able to quantify the hospital management practice is the precondition for conducting quantitative research on hospital management and its relationship with quality of care and other clinical outcomes. The World Management Survey (WMS) first developed a management survey instrument (the WMS method) to measure the management practice in manufacturing firms. ${ }^{[12-14]}$ A modified WMS version was used to measure the management practice in the medical settings, first in 104 public and 22 private hospitals in the United Kingdom, and later in 1,200 hospitals in 7 countries. ${ }^{[15-17]}$ These studies demonstrated that the management performance of these hospitals was related to their medical quality, medical service accessibility, patient satisfaction, and financial performance. However, the WMS method requires professional interviewers with expertise in hospital/health organization management and business. Thus, the WMS has limited practical utility in developing countries where the human resources with expertise in health system research and hospital management practices are often lacking.

In 2009, China launched a new healthcare reform designed to establish a basic health system that can provide safe, effective, convenient and low-cost health services to all Chinese people. ${ }^{[18]}$ After 7 years, the results are still not satisfying and hardly to be conclude as a success. The healthcare costs have been increasing much faster than the GDP growth; the share of hospitals in total health spending in China went up from $56 \%$ in 1990 to $63 \%$ in 2012 ; patients often received more prescriptions than they need and underwent unnecessary procedures that did not improve health outcomes; dissatisfaction with the quality of care was increasing, especially for primary care. ${ }^{[19,20]}$ During the period, there were also government and non-government quality of care improvement projects taking place, but often without encouraging results. ${ }^{[21]}$ The reasons for this failure may be due, in part, to a lack of knowledge of micro-level hospital management practices and how these practices are linked to the outcomes. Therefore, an objective, easy to apply, standardized method of quantifying hospital management and its relationship with quality of care and clinical outcomes is needed. This study describes the development of the HMP rating scale and evaluates its feasibility, reliability and validity.

\section{Methods}

\subsection{Development of the HMP rating scale}

Our first step was to establish a study group of 6 researchers with a background in public health and health management. After having systematically reviewed literatures about the current methods of hospital management evaluation, the study group concluded that the new HMP scale should be multi-facet and the WMS framework should be used to guide the development. Unlike the WMS method that consists of 2 levels of measurements, the HMP scale framework consists of 3 level measurements: dimensions, indicators and sub-indicators. The 4 dimensions of the HMP scale are defined exactly the same as the 4 areas of the WMS method: target management, operations management, performance management and talent management. At the second level of measurement, the WMS methods has 18 indicators (called "dimensions" in the WMS method) and the HMP scale has 17 indicators. Most of these indicators are the same or similar except for the three of the WMS dimensions that are not listed as an indicator in the HMP scale, including communication among staff, technology adoption and monitoring errors/safety. However, communication among staff and technology adoption are included in the sub-indicators of the HMP scale under different indicators. For example, under the indicator "Department performance appraisal" we defined the sub-indicator "Discussion and follow-up of appraisal results" to reflect the communication among staff. We have other sub-indicators to reflect communication among staff too. The HMP scale add three indicators that are not included in the WMS methods, including target setting, target sharing and uneven workload, to better fit the Chinese hospital management practices. For example, due to the China unique social political system, many Chinese hospital directors set their targets as the requirements from the government, without analysis of the market information, competitions from their counterparts, or their own competency. Due to the same reason, there are often not much discussions between hospital directors and the staff for either setting or implementing the targets, and uneven workload is frequently seen between departments or individuals. The third level measurements of the HMP scale are 47 sub-indicators under the 17 indicators (see Table 1). They are detailed descriptions of the hospital management practices linked closely back to the indicators, and at the same time they should be able to be defined by information collected through simple questions to the relevant hospital staff. 
Table 1. Framework of HMP scale

\begin{tabular}{|c|c|c|}
\hline Dimensions & Indicators & Sub-indicators \\
\hline \multirow{4}{*}{$\begin{array}{l}\text { Target } \\
\text { management }\end{array}$} & - Target balance & $\begin{array}{l}\text { - Comprehensiveness of targets } \\
\text { - Consistency between short- and long-term targets } \\
\text { - Consistency between department plan and hospital plan }\end{array}$ \\
\hline & - Target setting & $\begin{array}{l}\text { - The bases for target setting } \\
\text { - Participation of hospital directors in department annual plan setting }\end{array}$ \\
\hline & - Targets sharing & $\begin{array}{l}\text { - Awareness of hospital long-term targets } \\
\text { - Awareness of hospital annual plan } \\
\text { - Identity of hospital long-term targets } \\
\text { - Identity of department annual plan }\end{array}$ \\
\hline & - Target stretch & - Target stretch \\
\hline \multirow{5}{*}{$\begin{array}{l}\text { Operations } \\
\text { management }\end{array}$} & - Medical environment & $\begin{array}{l}\text { - Space sufficiency of outpatient area and inpatient ward area } \\
\text { - The rationality of layout }\end{array}$ \\
\hline & - Layout of services & $\begin{array}{l}\text { - Distance from the gate to emergency room } \\
\text { - Distance between surgery ward and operating room } \\
\text { - Placement of fall prevention signs }\end{array}$ \\
\hline & - Patient-centered services & $\begin{array}{l}\text { - Establishment of appointment register } \\
\text { - Establishment of "green channel" }\end{array}$ \\
\hline & - Clinical pathway & $\begin{array}{l}\text { - Availability } \\
\text { - Facilitating measures } \\
\text { - Perceived effects by responders }\end{array}$ \\
\hline & - Continuous quality improvement & $\begin{array}{l}\text { - Quality management policy } \\
\text { - Governance } \\
\text { - Specific measures of quality management }\end{array}$ \\
\hline \multirow{4}{*}{$\begin{array}{l}\text { Performance } \\
\text { management }\end{array}$} & $\begin{array}{l}\text { - Hospital Performance appraisal } \\
\text { - Department performance appraisal }\end{array}$ & $\begin{array}{l}\text { - Hospital performance appraisal system } \\
\text { - Criteria and publicity of performance appraisal } \\
\text { - Contents of appraisal } \\
\text { - Appraisal of department directors } \\
\text { - Discussion and follow-up of appraisal results }\end{array}$ \\
\hline & - Staff performance appraisal & $\begin{array}{l}\text { - Contents of appraisal } \\
\text { - Methods of appraisal } \\
\text { - Discussion of appraisal results }\end{array}$ \\
\hline & - Penalties on staff with dissatisfied performance & $\begin{array}{l}\text { - Verbal criticism } \\
\text { - Discussion of problems with staff } \\
\text { - Deduction of bonus } \\
\text { - Re-training } \\
\text { - Remove from original post }\end{array}$ \\
\hline & - Uneven workload & $\begin{array}{l}\text { - Uneven workload between departments } \\
\text { - Uneven workload within department }\end{array}$ \\
\hline \multirow{3}{*}{$\begin{array}{l}\text { Talent } \\
\text { management }\end{array}$} & - Rewarding & $\begin{array}{l}\text { - Bonus } \\
\text { - Training opportunities } \\
\text { - Promotion } \\
\text { - Spiritual incentives }\end{array}$ \\
\hline & - Staff satisfaction & $\begin{array}{l}\text { - Salary } \\
\text { - Working environment } \\
\text { - Career development }\end{array}$ \\
\hline & - Attracting talent & $\begin{array}{l}\text { - Talent recruitment } \\
\text { - Attracting talents }\end{array}$ \\
\hline
\end{tabular}


To develop and define the indicators and sub-indicators according to Chinese hospital practices, weekly seminars of the working group were held over four months to discuss and reach consensus. Afterwards, the pre-test was carried out among 12 hospital staff in a tertiary hospital in Beijing, to determine the acceptability of the scale and optimize the structure of it. Then, feedback from expert reviewers and group discussions served to revise the sub-indicators. Formal evaluations, as described below, were performed to finalize the HMP scale.

Unlike the WMS method using professionals to interview relevant employees at the target hospitals, our HMP scale is designed to use four self-administered questionnaires to collect the information on HMP by a trained lay person from 4 employees, with different roles, of a hospital; namely the director or deputy director of hospital, the director of medical affair management office, the director of cardiology department, and a cardiologist. In addition to the questionnaires, we also requested a list of hospital management documents, including the long-term work plan, annual action plan, performance appraisal policy documents and quality of care assurance policy documents. Data we collected included both encoded data (those collected with closed questions of the questionnaire) and non-encoded data (those collected with open questions of the questionnaire and with hospital administration policy documents). To derive a score for each sub-indicator, we first coded all uuencoded information. Two trained coders extracted key words from questions and documents and then assigned them corresponding numeric codes. A consensus conference was used to resolve reviewer discrepancies. We used the raw codes of answers to closed questions directly. All codes were entered into a database for further calculation of the HMP scores. The Hospital Management Rating Criteria was developed for rating the HMP score of each hospital, in which each sub-indicator was linked to one or multiple information sources, either from questionnaires or hospital management documents or both.

Each sub-indicator was scored, ranging from 0 to 1 , with indicator scores obtained as the average score of the subindicators under the same indicator, which also ranged between 0 and 1 , and dimension scores were the sum of the indicators under the same dimension. Thus, the full scores of 4 dimensions were 4, 5, 5 and 3 respectively for the target management, operations management, performance management and talent management. Thus, the overall score was the sum of the dimension scores, with higher scores representing better management practices. Finally, the scores were transformed into a 0-100 scale. The questionnaires used for data collection and criteria for coding/scoring are available through contact with the corresponding author.

\subsection{Evaluation of the HMP rating scale}

\subsubsection{Participants}

Participants were recruited from the Third Phase of the Clinical Pathways in Acute Coronary Syndromes Program (CPACS-3), ${ }^{[22]}$ a stepped-wedge cluster-randomized trial conducted in 104 hospitals across China. We conducted two cross-sectional surveys among the study hospitals, in year 2013 and 2014 respectively, in order to evaluate feasibility, reliability and validity of the HMP scale. Test-retest reliability was evaluated using the data of both years, whereas the others using the data of 2013 only. Participants were invited from all 101 hospitals that stayed in CPACS-3 main study when the sub-project initiated. Four staff members with different roles from each hospital were invited to participate, including the hospital director (or deputy director), the head of the cardiology department, a senior cardiologist and the director of the medical affair management office.

\subsubsection{Outcomes and statistical methods}

The feasibility of the survey instrument was documented from two measures: the response rate and the response time. ${ }^{[23]}$ The former was defined as the number of hospitals that provided completed questionnaires divided by the total number of hospitals and the latter as the mean duration (in days) that hospitals took to complete and return the survey.

Reliability was examined by using the split-half reliability to determine the internal consistency of the instrument while Cronbach' $\alpha$ reliability and test-retest reliability was used to assess the consistency of the measure. We repeated the assessment with the same method after 1 year and there were 83 hospitals participating both assessments and hence provided data for the test-retest reliability evaluation.

In order to establish construct validity, we performed exploratory factor analysis to examine the rationality of structure between the indicators and sub-indicators within each dimension. Factors were extracted using the principal components analysis with an eigenvalue lager than 1. Each subindicator should have a high loading $(>40 \%)$ on a given factor, and lower loadings on the others. If the ideal structure of the scale is consistent with the empirical structure after orthogonal varimax rotation, then it is considered with good construct validity.

Content validity was evaluated with correlation analysis for sub-indicators in each dimension on the representativeness and independence. The representativeness was assessed by the correlation coefficient between each sub-indicator and its affiliated indicator. A sub-indicator with correlation coefficient less than $0.4^{[23]}$ was modified or deleted. To establish independence, a sub-indicator was related only to the indica- 
tor it belongs. Any sub-indicators showing higher correlation coefficient (more than 0.4 ) with indicators other than its affiliated ones indicated poor independence and were deleted.

Discriminant validity was evaluated by comparing the overall management practice score between hospitals grouped by widely accepted outcomes of hospital management such as annual financial revenue, bed utilization rate, and the number of medical conditions which used clinical pathways.

All data were double entered and checked for accuracy. Only $2.1 \%$ of data had missing values due to the hospital confidentiality requirements and information incompleteness. We used the simple mean imputation and item mean imputation procedures to impute the missing data. ${ }^{[24]}$ Data were ana- lyzed using SPSS 20.0. Qualitative variables were expressed as percentages and quantitative variables as mean $(S D)$ or median (IQR). Student's $t$ test was used to compare two means and $\chi^{2}$ test was used to compare two percentages. $P$-values were two-tailed and the significance level for all statistical procedures was set at .05 .

\section{Results}

\subsection{Characteristics of the study hospitals}

Among the 101 eligible hospitals, 86 hospitals participated in the initial survey in 2013 with a response rate of $85 \%$. The second survey was re-administered in 2014. Descriptive characteristics of participating hospitals are presented in Table 2.

Table 2. Characteristics of the hospitals participated in the study, 2013

\begin{tabular}{ll}
\hline Characteristics of the hospitals & \\
\hline Location (n [\%]) & $31(36.0)$ \\
- East (most developed) & $38(44.2)$ \\
- Central (developed) & $17(19.8)$ \\
- West (under developed) & $674 \pm 271$ \\
Number of staff (mean $\pm S D$ ) & $532 \pm 222$ \\
Number of health professionals (mean $\pm S D)$ & $502 \pm 222$ \\
Number of hospital beds (mean $\pm S D)$ & $98.0 \%(85.4 \%, 116.4 \%)$ \\
Hospital bed occupancy rate (IQR) & $189(109,279)$ \\
Outpatient volume (thousand, median [IQR]) & $23(14,34)$ \\
Inpatient volume (thousand, median [IQR]) & $8.4 \pm 1.8$ \\
Hospital stay (days, mean $\pm S D$ ) & $19.2(12.7,29.8)$ \\
Hospital revenue (million USD*, median[IQR]) & $82(36,153)$ \\
Number of in-hospital deaths in the past year (median [IQR]) & $23(10,46)$ \\
Number of clinical pathways implemented (median [IQR]) & \\
\hline
\end{tabular}

Note. ${ }^{*}$ The current exchange rate of RMB to US Dollar in 2013 was 6.5

Table 3. Split-half reliability and Cronbach' $\alpha$ reliability for the overall HMP score and each dimension score

\begin{tabular}{llll}
\hline Dimensions & Number of sub-indicators & Split-half reliability & Cronbach' $\alpha$ reliability \\
\hline Target management & 10 & 0.798 & 0.597 \\
Operations management & 13 & 0.712 & 0.566 \\
Performance management & 15 & 0.679 & 0.683 \\
Talent management & 9 & 0.875 & 0.803 \\
Overall & 47 & 0.910 & 0.850 \\
\hline
\end{tabular}

\subsection{Feasibility}

The first survey took 27 days from $20^{\text {th }}$ February to $18^{\text {th }}$ March in 2013, and 86 hospitals $(85.1 \%)$ responded. These 86 hospitals were invited in the second survey, which lasted for 30 days from the $3^{\text {rd }}$ of March 3 to April 1, 2014 with 83 hospitals $(96.5 \%)$ responding. Thus, a total of 83 hospitals $(82.2 \%)$ responded to both surveys and the mean time of responding was 28.5 days.

\subsection{Reliability}

\subsubsection{Spilt-half reliability}

The spilt-half reliability coefficient was 0.910 for the overall HMP score and ranged from the lowest in performance management (0.679) to the highest in talent management (0.875) 
for each dimension (see Table 3).

\subsubsection{Cronbach' $\alpha$ reliability}

The Cronbach' $\alpha$ reliability coefficient was 0.850 for overall HMP score and ranged from the lowest in the operations management (0.566) to the highest in the talent management
(0.803).

\subsubsection{Test-retest reliability}

The test-retest ICC of the overall HMP score was 0.801. As for dimensions, please refer to Table 4 for details.

Table 4. The test-retest reliability among 83 hospitals participating the study

\begin{tabular}{lllll}
\hline Dimensions & $\begin{array}{l}\text { Baseline score } \\
(\text { Mean } \boldsymbol{S} \boldsymbol{S} \boldsymbol{D})\end{array}$ & $\begin{array}{l}\text { Second score } \\
(\text { Mean } \pm \boldsymbol{S D})\end{array}$ & $\begin{array}{l}\text { Difference } \\
(\text { Mean } \pm \boldsymbol{S D})\end{array}$ & $\begin{array}{l}\text { Test-retest } \\
\text { reliability }(\text { ICC) }\end{array}$ \\
\hline Target management & $39.5 \pm 12.8$ & $38.4 \pm 12.8$ & $1.1 \pm 10.9$ & 0.779 \\
Operations management & $59.4 \pm 14.7$ & $59.8 \pm 13.5$ & $-0.4 \pm 10.1$ & 0.855 \\
Performance management & $49.6 \pm 13.6$ & $48.8 \pm 14.1$ & $0.8 \pm 14.9$ & 0.592 \\
Talent management & $58.0 \pm 18.1$ & $52.2 \pm 16.4$ & $5.9 \pm 17.4$ & 0.662 \\
Overall & $51.6 \pm 11.0$ & $50.2 \pm 10.2$ & $1.4 \pm 8.6$ & 0.801 \\
\hline
\end{tabular}

Table 5. Main results of factor analysis by each dimension of the HMP scale

\begin{tabular}{|c|c|c|c|c|c|c|c|c|}
\hline \multirow{2}{*}{$\begin{array}{l}\text { Dimensions } \\
\text { of HMP }\end{array}$} & \multirow{2}{*}{ Results } & \multicolumn{6}{|c|}{ Principal Component Factors } & \multirow{2}{*}{$\begin{array}{l}\text { Accumulated \% } \\
\text { of total variance } \\
\text { distributed }\end{array}$} \\
\hline & & First & Second & Third & Fourth & Five & Six & \\
\hline \multirow{2}{*}{ Target } & $\begin{array}{l}\text { Corresponding } \\
\text { indicators }\end{array}$ & Indicator 1 & $\begin{array}{l}\text { Indicators } \\
3 \& 4\end{array}$ & Indicator 2 & & & & \\
\hline & $\begin{array}{l}\% \text { of total variance } \\
\text { distributed }\end{array}$ & 25.5 & 24.9 & 11.5 & & & & 62.0 \\
\hline \multirow{2}{*}{ Operations } & $\begin{array}{l}\text { Corresponding } \\
\text { indicators }\end{array}$ & Indicator 5 & $\begin{array}{l}\text { Indicators } \\
1 \& 3\end{array}$ & Indicator 4 & Indicator 2 & & & \\
\hline & $\begin{array}{l}\% \text { of total variance } \\
\text { distributed }\end{array}$ & 19.5 & 18.2 & 15.2 & 11.2 & & & 64.1 \\
\hline \multirow{2}{*}{ Performance } & $\begin{array}{l}\text { Corresponding } \\
\text { indicators }\end{array}$ & $\begin{array}{l}\text { Indicators } \\
3 \& 4\end{array}$ & Indicator 2 & $\begin{array}{l}\text { Indicators } \\
3 \& 4\end{array}$ & Indicator 4 & Indicator 5 & Indicator 1 & \\
\hline & $\begin{array}{l}\% \text { of total variance } \\
\text { distributed }\end{array}$ & 12.8 & 12.7 & 10.4 & 10.0 & 9.5 & 8.1 & 63.5 \\
\hline \multirow{2}{*}{ Talent } & $\begin{array}{l}\text { Corresponding } \\
\text { indicators }\end{array}$ & Indicator 1 & $\begin{array}{l}\text { Indicators } \\
2 \& 3\end{array}$ & & & & & \\
\hline & $\begin{array}{l}\% \text { of total variance } \\
\text { distributed }\end{array}$ & 31.0 & 30.2 & & & & & 61.2 \\
\hline
\end{tabular}

Note. When an indicator appears in two or more factors, it means that some sub-indicators under this indicator are split into different factors. The indicators are numbered in sequence corresponding to their sequence in the HMP scale (see the Table 1)

\subsection{Validity}

\subsubsection{Construct validity}

The Kaiser-Meyer-Olkin (KMO) indexes were greater than 0.5 and the Bartlett's Test of Sphericity was significant $(p<.05)$ for all dimensions. The number of factors extracted from the target, operations, performance and talent management dimensions after orthogonal varimax rotation were $3,4,6,2$ respectively and corresponding to $4,5,5$ and 3 indicators of the HMP scale, explaining over $60 \%$ of the total variance in each dimension. The results showed that the structure of the dimensions were basically consistent with the rotated principle component factors, except for the
Performance Indicators "Staff performance appraisal" and "Penalties on staff with dissatisfied performance", whose affiliated sub-indicators were loaded on multiple factors (see Table 5).

\subsubsection{Content validity}

The correlation coefficients between most sub-indicators and their parent indicators were between 0.7 and 0.9 except for two sub-indicators, the "Remove from original post" ( $r=$ $0.318)$ and "Placement of fall prevention signs" $(r=0.374)$. On the other hand, weak correlations ( $r$ less than 0.4 ) existed between most sub-indicators and the non-parent indicators. 


\subsubsection{Discriminant validity}

We divided 86 hospitals into two groups according to the median of the financial revenue, hospital bed occupancy rate, and the number of diseases in which clinical pathways were used. Table 6 shows that hospitals with higher financial revenue, higher rate of average bed occupancy as well as more clinical pathways implementation had significantly higher overall management scores compared to hospitals with lower financial revenue, lower bed occupancy and fewer clinical pathways.

Table 6. Discriminant validity of HMP scale

\begin{tabular}{llll}
\hline Variable & Group & $\begin{array}{l}\text { HMP overall score } \\
(\text { mean } \pm \text { SD) }\end{array}$ & $\boldsymbol{p}$-value \\
\hline $\begin{array}{l}\text { Financial revenue } \\
\text { (million USD) }\end{array}$ & $<19.2$ & $47.2 \pm 10.7$ & $<.001$ \\
Bed occupancy rate & $<98$ & $47.7 \pm 10.5$ & \\
$(\%)$ & $\geqslant 98$ & $54.9 \pm 10.4$ & .002 \\
$\begin{array}{l}\text { The number of } \\
\text { clinical pathways }\end{array}$ & $\geqslant 23$ & $48.3 \pm 11.4$ & \\
\hline
\end{tabular}

\section{Discussion}

This study describes the development of a scale designed to quantitate the quality of hospital management practice. We evaluated the scale systematically for its reliability and validity. Both high split-half reliability (coefficient $=0.91$ ) and high Cronbach' $\alpha$ reliability (coefficient $=0.85$ ) demonstrate its high degree of internal consistency.

We used several methods to evaluate the validity. The construct validity was found to be high and consistent with its theoretical conception. Among 17 indicators, only 2 indicators showed that sub-indicators were not grouped together. The sub-indicator "Discussion of appraisal results" under the indicator "Staff performance appraisal" fell into Factor 3, which contained the sub-indicators "Verbal criticism" and "Discussion of problems with staff" under the indicator "Penalties on staff with dissatisfied performance". The meaning of the sub-indicators are close and were grouped into one factor. However, they are used to measure different aspects of the hospital management practice. Also, we found that the sub-indicators of the indicator "Penalties on staff with dissatisfied performance" were split into 3 factors. Careful examination of the sub-indicators revealed that it is reasonable to separate them into three parts: the soft measures (sub-indicators "Verbal criticism" and "Discussion of problems with staff"), hard measures (sub-indicator "Retraining"), and harsh measures (sub-indicators "Deduction of bonus" and "Remove from original post") to punish the dissatisfied performance.

Our results showed that the application of the HMP scale Published by Sciedu Press was feasible, with the mean time of responding less than a month. Only one investigator was used to manage the data collection and two evaluators were used for the subsequent coding when using the HMP scale. And these study personnel need not to be experts in health management. By mailing the questionnaires to 4 staffs with defined roles in the hospital, HMP data could be collected comprehensively and in a short time, with less subjective biases.

To our knowledge, our HMP rating scale is the first novel instrument specifically developed to quantify the daily managerial practices of hospitals without global and subjective judgements made by evaluators. The successful development of the HMP scale indicates that the management practices of hospitals can become a measurable entity. Both the overall management practices and each of the four dimensions could be measured and evaluated, which enable the hospital authorities to have a comprehensive and deeper view of the hospital management practices. By using the HMP scale, it is possible for hospitals to recognize the strengths, weaknesses and need for change of their management practice. It is also helpful to make comparisons between hospitals in terms of their hospital management practices.

While compared with the WMS method, the major feature of our HMP scale is that the WMS method uses open-ended questions asked by expert interviewers and a score is given according to the understanding of the interviewers to the management of the hospital against to the criteria set for the evaluation, ${ }^{[25]}$ while our HMP scale is based on information collected through questionnaires with specific questions and pre-defined response options. Also, our method does not require the survey staff have expertise in hospital or health management or experience in qualitative interview techniques.

\section{Limitations}

First, our study hospitals were not randomly selected, in particular they were all resource-limited county level hospitals. However, they were scattered in 15 provinces across China and all were public hospitals. The indicators and subindicators in the HMP scale were developed according to the common management practices in all Chinese hospitals including tertiary hospitals. Second, for the test-retest reliability we repeated our survey of the hospitals in 12 months rather than 2-4 weeks, which is longer than other studies and may be susceptible to changes in hospital work plans, which are generally updated on an annual base. Third, the department-level and doctor-level respondents selected all came from cardiology department, which may not be representative of all departments throughout the hospital. However, because the hospital management practices are mostly 
centralized at the hospital level and less diverse at the department level, this is unlikely to represent a major concern. Last, due to the differences in culture, political environment, hospital structure, funding sources, etc. the applicability and generalizability of the HMP scale in other countries need to be considered carefully. For example, the measurement tools used in the U.S. focus on patient error in terms of quantifying quality. Indicators such as patient and staff satisfaction data are often utilized, with financial reimbursement sometimes driving the institutional goals and metrics. However, only few HMP indicators are different from the WMS methods. With necessary modifications, we believe that the instrument should be applicable in other settings.

\section{Conclusions}

This study describes the development and evaluation of reliability and validity of a new instrument. The results demonstrated that the HMP rating scale was reliable, valid, and responsive in this preliminary study, and future studies with larger sample size and in different settings are required to confirm the study findings.

\section{ACKNOWLEDGEMENTS}

The authors would like to thank all survey participants from all participating hospitals for their great contribution to the study.

\section{FINDING}

The source of funding used to support the CPACS-3 and its sub-project is from Sanofi, China, through an unrestricted research grant. The funders had no role in study design, data collection and analysis, decision to publish, or preparation of the manuscript.

\section{ETHICS APPROVAL}

Ethical approval was obtained on 30 June 2011 from the Peking University Institutional Review Board (No.IRB00001052-11037).

\section{AUTHORS'CONTRIBUTION}

Yidan Zhu, Ruya Guo, Lixia Dou and Yifei Zhao contributed equally to this manuscript.

\section{CONFLICTS OF INTEREST Disclosure}

The authors declare they have no conflicts of interest.

\section{REFERENCES}

[1] Bradley EH, Curry LA, Spatz ES, et al. Hospital strategies for reducing risk-standardized mortality rates in acute myocardial infarction. Annals of Internal Medicine. 2012; 156(9): 618-26. https: //doi.org/10.7326/0003-4819-156-9-201205010-00003

[2] McConnell KJ, Lindrooth RC, Wholey DR, et al. Modern Management Practices and Hospital Admissions. Health Economics. 2016; 25(4): 470-85. https://doi.org/10.1002/hec. 3171

[3] Shortell SM, Singer SJ. Improving patient safety by taking systems seriously. JAMA. 2008; 299(4): 445-7. https://doi.org/10.1 $001 /$ jama. 299.4.445

[4] Shortell SM, Rundall TG, Hsu J. Improving patient care by linking evidence-based medicine and evidence-based management. JAMA 2007; 298(6): 673-6. https://doi.org/10.1001/jama.298.6 .673

[5] Roland M, Dudley RA. How Financial and Reputational Incentives Can Be Used to Improve Medical Care. Health Services Research. 2015; 50(Suppl 2): 2090-115. https ://doi .org/10.1111/1475 $-6773.12419$

[6] Mannion R, Davies HT, Marshall MN. Cultural characteristics of "high" and "low" performing hospitals. Journal of Health Organization and Management. 2005; 19(6): 431-9. https : //doi.org/10 $.1108 / 14777260510629689$

[7] Van Leijen-Zeelenberg JE, Brunings JW, Houkes I, et al. Using Lean Thinking at an otorhinolaryngology outpatient clinic to improve quality of care. The Laryngoscope. 2016; 126(4): 839-46. https://doi.org/10.1002/lary.25741

[8] Mort EA, Demehin AA, Marple KB, et al. Setting quality and safety priorities in a target-rich environment: an academic med- ical center's challenge. Academic Medicine: Journal of the Association of American Medical Colleges. 2013; 88(8): 1099-104. https://doi.org/10.1097/ACM.0b013e31829a3ee8

[9] Wagner C, Mannion R, Hammer A, et al. The associations between organizational culture, organizational structure and quality management in European hospitals. International Journal for Quality in Health Care. 2014; 26(Suppl 1): 74-80. https://doi.org/10.1 093/intqhc/mzu027

[10] Hoff T, Jameson L, Hannan E, et al. A review of the literature examining linkages between organizational factors, medical errors, and patient safety. Medical Care Research and Review. 2004; 61(1): 3-37. https ://doi.org/10.1177/1077558703257171

[11] Lega F, Prenestini A, Spurgeon P. Is management essential to improving the performance and sustainability of health care systems and organizations? A systematic review and a roadmap for future studies. Value in Health. 2013; 16(1 Suppl): S46-51. https: //doi.org/10.1016/j.jval.2012.10.004

[12] Bloom N, Van Reenen J. Measuring and explaining management practices across firms and countries. National Bureau of Economic Research. 2006. https://doi .org/10.3386/w12216

[13] Bloom N, Van Reenen J. Why do management practices differ across firms and countries? The Journal of Economic Perspectives. 2010; 24(1): 203-24. https://doi.org/10.1257/jep.24.1.203

[14] Van Reenen J, Bloom N. New Approaches to Measuring Management and Firm Organization. 2010.

[15] Bloom N, Sadun R, Van Reenen J. Does Management Matter in Healthcare. London School of Economics Working Paper. 2013.

[16] Carter K, Dorgan S, Layton D. Why hospital management matters. Health International. 2011; 11: 81-8. 
[17] Dorgan S, Layton D, Bloom N, et al. Management in healthcare: why good practice really matters. London: McKinsey and Company/London School of Economics; 2010.

[18] Chen Z. Launch of the health-care reform plan in China. Lancet. 2009; 373(9672): 1322-4. https://doi .org/10.1016/S0140-6 736 (09) 60753-4

[19] World Bank Group. Deepening Health Reform in China: Building High-Quality and Value-Based Service Delivery. Washington, DC: World Bank.; 2016.

[20] Yip W, Hsiao W. Harnessing the privatisation of China's fragmented health-care delivery. Lancet. 2014; 384(9945): 805-18. https://doi.org/10.1016/S0140-6736(14)61120-X

[21] Ranasinghe I, Rong Y, Du X, et al. System barriers to the evidencebased care of acute coronary syndrome patients in China: Qualitative analysis. Circ Cardiovasc Qual Outcomes. 2014; 7(2): 209-16. https://doi.org/10.1161/CIRCOUTCOMES.113.000527

[22] Li S, Wu Y, Du X, et al. Rational and design of a stepped-wedge cluster randomized trial evaluating quality improvement initiative for reducing cardiovascular events among patients with acute coronary syndromes in resource-constrained hospitals in China. Am Heart J. 2015; 169(3): 349-55. https://doi.org/10.1016/j.ahj. 2014 .12 .005

[23] Huang ZJ, Tian M, Dai SY, et al. Feasibility, reliability and validity of the Chinese simplified version of the MOS-HIV health survey among AIDS patients in China. Quality of Life Research: An International Journal of Quality of Life Aspects of Treatment, Care and Rehabilitation. 2013; 22(2): 403-7. https://doi.org/10.1007/ s11136-012-0148-0

[24] Twisk J, de Vente W. Attrition in longitudinal studies. How to deal with missing data. Journal of Clinical Epidemiology. 2002; 55(4): 329-37. https://doi .org/10.1016/S0895-4356(01)0 0476-0

[25] McConnell KJ, Lindrooth RC, Wholey DR, et al. Management practices and the quality of care in cardiac units. JAMA Internal Medicine. 2013; 173(8): 684-92. https://doi.org/10.1001/jamaintern med.2013.3577 